\title{
Galicia Dixital. Una exposición de patrimonio e-tangible. El Museo Vacío.
}

\author{
Luis A. Hernández Ibáñez \\ VideaLab | Grupo de Visualización Avanzada en Arquitectura, Ingeniería Civil y Urbanismo \\ Universidade da Coruña - España
}

\begin{abstract}
Resumen
Galicia Dixital es una exposición que abrió sus puertas en Santiago de Compostela para mostar a sus visitantes, a través de las nuevas tecnologías audiovisuales la cultura y el patrimonio de esta comunidad autónoma, a la vez que se les ilustra en el uso y aplicaciones de tecnologías de vanguardia. Este articulo describe algunas de sus instalaciones y en especial el Museo Vacio, un entorno de realidad virtual completamente inmersiva donde el usuario puede caminar físicamente visitando mundos virtuales, describiendo algunos de los ejemplos de aplicación del mismo dentro de la exposición.
\end{abstract}

Palabras Clave: EXPOSICIÓN; PATRIMONIO CULTURAL; INTERFACES NATURALES; REALIDAD VIRTUAL.

\begin{abstract}
Galicia Dixital is an exhibition located in Santiago de Compostela whith the mission to show the culture and heritage of this region through the use of new audiovisual technologies, whilst to demonstrate the use and applications of avant-garde technology. This paper describes some of the installations present there with special emphasis in The Empty Museum, a fully immersive virtual reality installation where the user can walk physically visiting virtual worlds. A group of examples of contents designed for this medium will be also described.
\end{abstract}

Key words: $\quad$ EXHIBITION; CULTURAL HERITAGE; NATURAL INTERFACES; VIRTUAL REALITY.

\section{Introducción}

La aplicación de las tecnologías audiovisuales en el ámbito de la museística ha tenido en los últimos años una tendencia creciente. Conscientes de la capacidad del medio audiovisual para complementar lo expuesto, los conservadores de los museos y comisarios de exposiciones han hecho uso de la imagen, el vídeo y la multimedia para aportar valor añadido a las piezas objeto de muestra, e ilustrar conceptos de cara a la mejor interpretación de las exposiciones por parte de los visitantes.

Aunque cualquier tema es susceptible aprovechar la potencia de las nuevas tecnologías audiovisuales, el patrimonio histórico y cultural es especialmente sensible a su adaptación, por cuanto abarca un amplio espectro de elementos que requieren de un complemento narrativo para su interpretación que va desde objetos a costumbres y desde edificios a rutas de peregrinación.

Aunque en la inmensa mayoría de los museos, el uso de tecnologías audiovisuales representa tan solo un complemento, las tendencias de cambio están haciendo que surja un nuevo concepto de espacio expositivo, centrado más en la experimentación que en la muestra y empiezan a ser numerosos en todo el mundo los ejemplos de museos en los que la oferta de esta experiencia se basa en el uso de los nuevos medios, llegando a constituir éstos una parte fundamental y protagonista, e incluso exclusiva en algunos casos. Galicia Dixital constituye uno de los ejemplos pioneros de esa tendencia.

\section{Galicia Dixital}

La exposición Galicia Dixital nació en 2000, promovida por la Dirección Xeral de Comunicación Social y Audiovisual de la Sunta de Galicia buscando un doble objetivo. Por una parte servir como escaparate de divulgación al gran público de los medios audiovisuales más avanzados, a través de instalaciones realizadas por empresas y universidades gallegas y por otra divulgar una parte representativa de la cultura y el patrimonio de esta comunidad autónoma exclusivamente por medios digitales.

Este espacio museístico, alojado en el Monasterio de San Martín Pinario, en la céntrica plaza de la Inmaculada de Santiago de Compostela, cuenta con varias salas en las que se disponen diecinueve instalaciones por las que han pasado tecnologías de simulación y visualización por computador, visión estereoscópica, cine dinámico interfaces naturales y hápticos y realidad virtual.

Son de destacar entre estas instalaciones las proyecciones estereoscópicas con integración de imagen real y de síntesis realizadas por la empresa Enxebre Sistemas, que ilustran la calidad ambiental y promocionan la zona de los Ancares, la recreación de los fondos submarinos con su fauna autóctona desarrollada por Portico Comunicacion, y muy especialmente los trabajos del grupo MAR del Laboratorio de Sistemas de la 
Universidad de Santiago de Compostela. Este grupo ha llevado a cabo recreaciones por computador del conjunto histórico compostelano, que es posible admirar sintiendo incluso la llovizna en la ciudad o desplazarse sobre sus tejados en una montaña rusa virtual. El grupo MAR asimismo ha recreado en esta exposición el funcionamiento del Botafumeiro (OTERO, 2007). Su última instalación dentro de este espacio expositivo "Las Carrilanas" aparece en estas actas.

Desde el Grupo de Visualización Avanzada de la Universidad de A Coruña (VideaLAB), la colaboración con esta exposición ha venido dándose desde sus orígenes, inicialmente con la recreación 3D de la Catedral de Santiago de Compostela en el siglo XIII (fig. 1) y el Sistema Avanzado de Navegación sobre Terrenos Interactivo (SANTI) (fig.2) que permitió desde aquellas fechas, el sobrevuelo sobre la geografía para contemplar la riqueza del paisaje gallego. (HERNANDEZ, 1999).

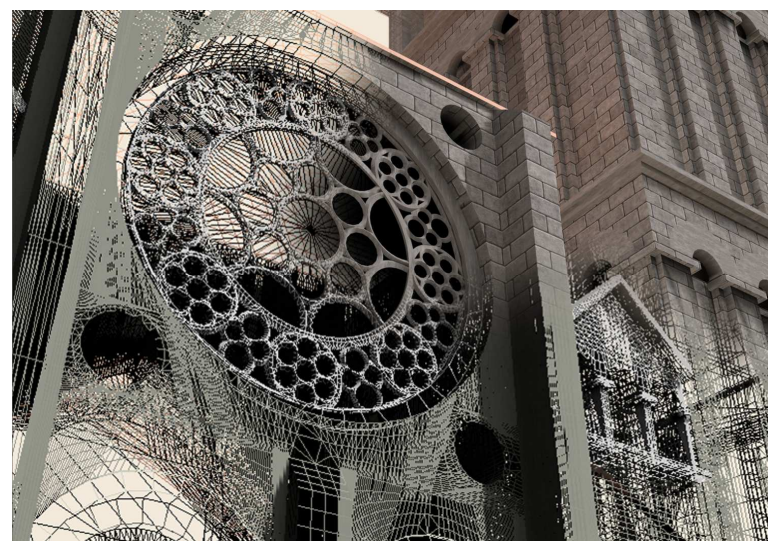

Figura 1. Recreación de la Fachada de la Catedral del Santiago en el siglo XIII

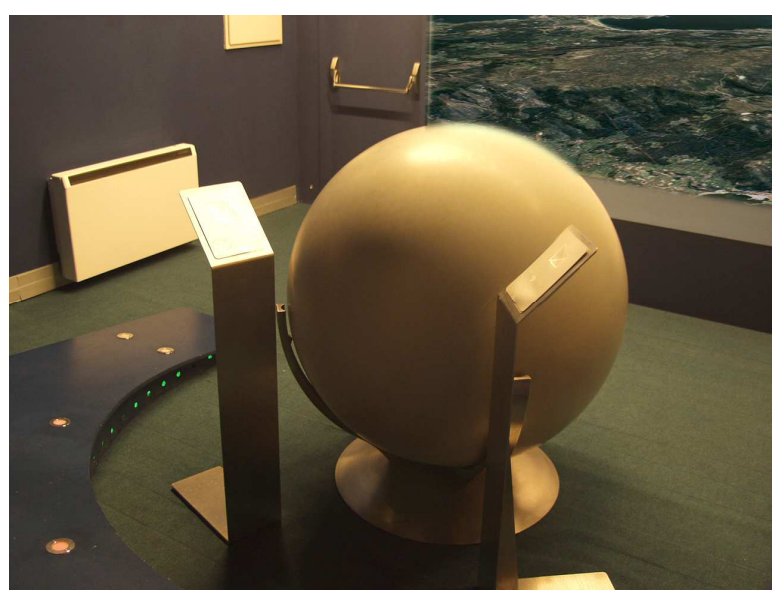

Figura 2.- Instalación SANTI

Además de estas aportaciones, el VideaLAB trabajó en la realización de varias instalaciones que hacen uso de tecnologías de video $360^{\circ}$, interfaces naturales y realidad virtual inmersiva que se describirán más adelante.

Fruto de esta colaboración entre la Administración Autonómica, las empresas y universidades gallegas fue posible ofrecer a los visitantes una visión escueta pero representativa del inmenso patrimonio cultural de Galicia, que ha ido describiendo edificios históricos en su pasado y presente, patrimonio ambiental, artes, costumbres, ritos y leyendas, un patrimonio rico y variado difícil de mostrar y aún más difícil de experimentar pero que se hace tangible mediante el uso de las tecnologías audiovisuales e interactivas avanzadas.

\section{Interfaces naturales}

En los últimos años, se están dedicando considerables esfuerzos en la búsqueda de formas de comunicación entre humanos y máquinas que ayuden a salvar esta brecha, en la línea de que sea la computadora la que perciba los deseos del usuario y actúe en consecuencia. Para ello, estas formas de interfaz deben extraer la información que necesitan a partir del análisis de las palabras, gestos y otras formas de lenguaje corporal que los humanos utilizamos de manera común para nuestra comunicación cotidiana.

En el diseño de aplicaciones para mostrar contenidos digitales en un museo basándose en interfaces naturales habrán de tenerse en cuenta los criterios generales de éstos, modulados por los condicionantes de la finalidad expositiva, buscando por tanto:

- La ausencia de dispositivos informáticos aparentes para realizar la comunicación.

- Aprovechar la curiosidad del usuario, ya que al fin y al cabo, es precisamente por ella por lo que se encuentra en un museo. El uso de formas novedosas de interfaz que provoquen el deseo de experimentación ayudará a captar el preciado bien de la atención del visitante.

- Evitar la necesidad de explicaciones sobre el funcionamiento del sistema o en todo caso reducirlas a unas pocas palabras. Un dispositivo adecuado debe dejar patente su modo de uso de manera inmediata o mejor aún, el usuario debe sentir que sabe usarlo aunque no lo haya visto nunca.

- Buscar la sorpresa agradable en la propia experiencia de la instalación, fascinando por su manejo, por sus contenidos o por una combinación de ambos. Varios autores hacen referencia a la similitud con la idea de "magia" para referirse a esta sensación en el ámbito expositivo. (MILEKIC, 2006)(JOCH, 2004)

- Proponer una serie de interacciones sencillas, que correspondan con gestos instintivos que posean un significado no afectado por barreras culturales o lingüísticas.

Todo ello no persigue otra cosa en el fondo que brindar al visitante una experiencia. A través de ella descubrirá de manera entretenida aquellas cosas que el museo pretendía contarle y para ello no se le ha pedido esfuerzo, sino tan solo curiosidad y un poco de su tiempo. Es con esa finalidad con la que desde VideaLAB se diseñaron para la exposición Galicia Dixital las siguientes instalaciones:

- Ventanas virtuales. La instalación se basa en pantallas colgantes, cada una de las cuales el usuario toma entre sus manos moviéndola en torno suyo como si de una ventana a otro lugar se tratase. A través de ella se muestran entornos 
urbanos que se ven siempre de manera coherente con la orientación en tres ejes del dispositivo que el usuario lleva en sus manos. (fig. 3).

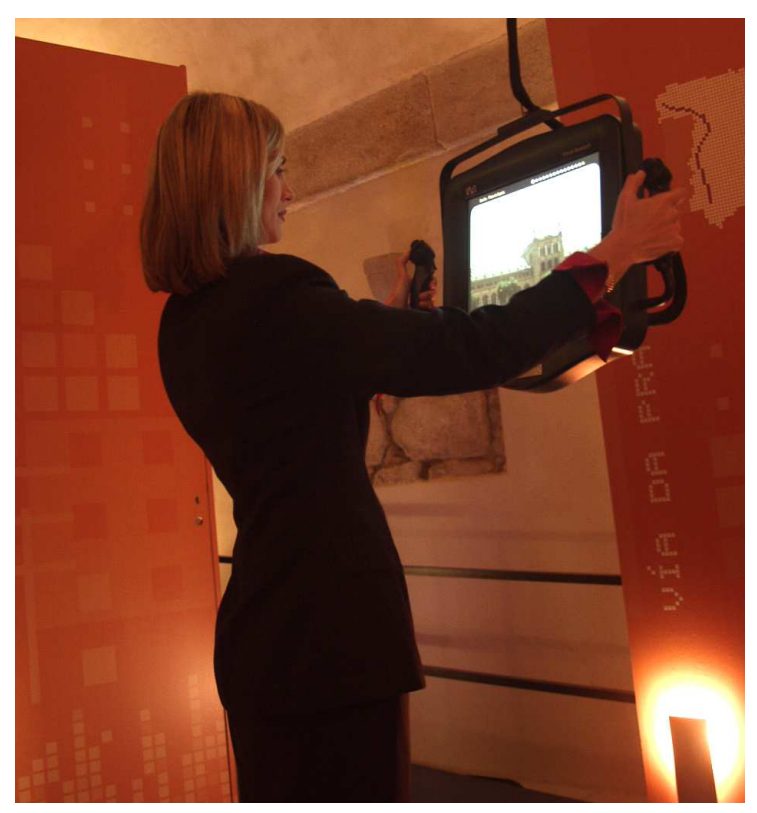

Figura 3. Ventanas virtuales

Para ello se utiliza un monitor WindowVR que contiene un sensor de orientación. El contenido mostrado se basa en la idea de la imagen panorámica esférica, de forma que el movimiento del panorama se ajusta al movimiento de la ventana virtual en las manos del usuario. Para hacer la experiencia más realista, y no limitar la visión a panoramas estáticos, se utilizó una tecnología propia de grabación y reproducción de video en $360^{\circ}$ (HERNANDEZ, 2001) que fue implementada en las diferentes versiones de la instalación.

Los contenidos expuestos en esta instalación, que se renovaron periódicamente fueron: Capitales Europeas de la Cultura, Caminos de Santiago y Galicia y el Agua.

- Fuente encantada. La fuente encantada es una instalación ambientada en unas ruinas arcanas en la que los visitantes, en grupo, interactúan con sus manos con una "fuente" en la que viven personajes y aparecen elementos mágicos de la cultura popular. El sistema, basado en una retroproyección inferior y una captura y análisis de imagen superior permite la interacción simultánea de hasta nueve usuarios que trabajan en grupo para descubrir los secretos que se muestran en su superficie. (fig. 4)

El contenido de la misma hace referencia a los cuatro elementos $\mathrm{e}$ incluye inscripciones como petroglifos o pinturas rupestres que los visitantes deben descubrir en equipo mediante gestos diferentes según el elemento de la naturaleza con el que deben interactuar. Así, la fuente comienza mostrándose llena de agua con peces que viven en su interior y que escapan cuando los visitantes tocan con su mano la superficie o generan olas al pasar su brazo a lo largo de ella. El elemento tierra se ve representado por una capa de arena virtual que cubre toda la superficie de la fuente. Los usuarios eliminan la arena "limpiando" con sus manos, descubriendo la piedra grabada con petroglifos antiguos que se encuentra bajo ella para que finalmente el viento acabe con los últimos restos. En el caso del fuego, los visitantes dirigen llamas mágicas a distancia con las puntas de sus dedos sobre los surcos de la piedra grabada por la que fluyen regueros de lava que dotan de vida a las figuras allí representadas.

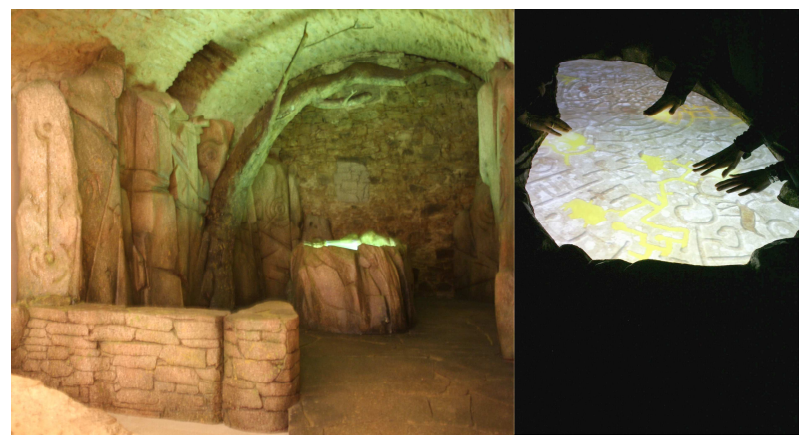

Figura 4. La Fuente Encantada

\section{Realidad Virtual. E1 Museo Vacío}

La Realidad Virtual, entendida en su sentido más inmersivo constituye un medio ideal para ubicar al visitante en lugares y situaciones imposibles de recrear en el mundo real, pero que pueden resultar de gran valor didáctico y descriptivo. Su uso sin embargo está muy limitado en el ámbito museístico por ser esta aún hoy una tecnología experimental. En ese sentido, el Museo Vacío se diseñó para potenciar la sencillez del sistema en su manejo y formas de interacción, a la vez que se ofrecía al usuario un equipamiento para ser llevado consigo atractivo y libre de cables que le permitiese transitar libremente por una sala vacía en apariencia, pero repleta de contenidos una vez que el visitante se ve inmerso en el espacio virtual. (Figura 5)

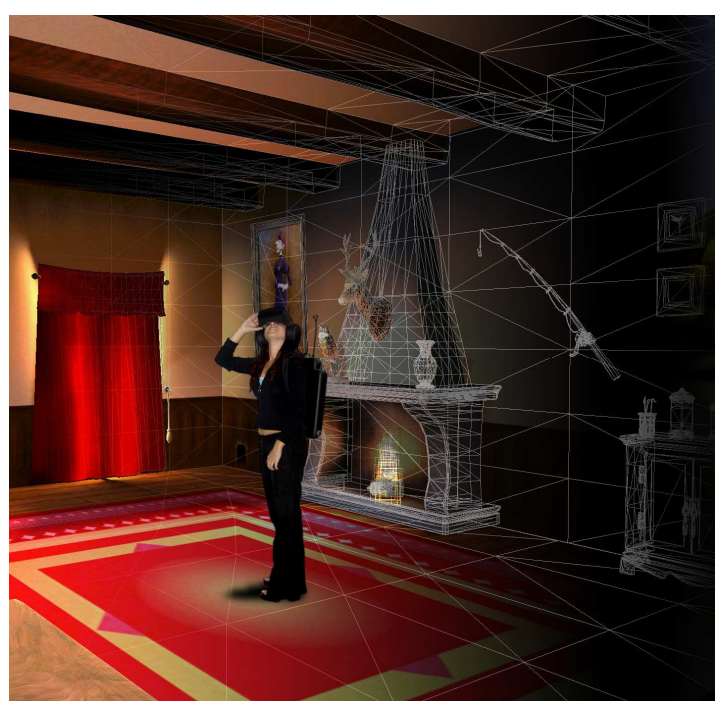

Figura 5. La experiencia del visitante en el Museo Vacio 
A grandes rasgos, el Museo vacío consta, a nivel de hardware, de dos subsistemas principales. El sistema base, que controla la ubicación de los usuarios en la sala y la orientación de sus cabezas por medio de dispositivos de seguimiento inalámbricos. Esta información es transmitida mediante red sin hilos a los sistemas satélites, que son portados por cada uno de los visitantes y que constan de una mochila que contiene un ordenador portátil, encargado de generar las imágenes del mundo virtual en función de la posición y orientaciones recibidas, y un casco de realidad virtual que pone ante sus ojos dichas imágenes y hace sonar el audio espacializado correspondiente. La descripción detallada de la instalación puede consultarse en la bibliografía (HERNANDEZ, 2003). La figura 4 muestra la instalación en Galicia Dixital.

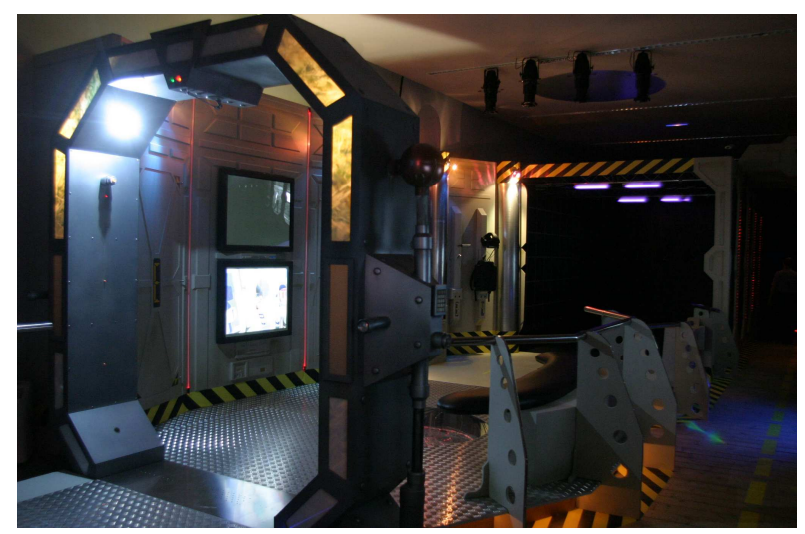

Figura 4.La instalación Museo Vacio en la exposición.

La interacción entre el usuario y el mundo virtual se lleva a cabo exclusivamente mediante el seguimiento de la atención e interés de aquel hacia los diferentes elementos expuestos. En todo momento, el sistema sabe en qué zonas se encuentra detenido el visitante y hacia donde mira de forma que con estos datos se activan los eventos correspondientes del mundo virtual: sonidos y locuciones, vídeos, animaciones de objetos, reproducción de comportamientos por parte de personajes virtuales o "teletransporte" a otro mundo virtual dentro del mismo espacio físico.

Desde la implementación del primer prototipo del sistema se han confeccionado para él una variedad de mundos virtuales que reflejan aspectos de la cultura y el patrimonio histórico de Galicia desde perspectivas originales. Entre ellos podrían citarse los siguientes:

- Mundo de la Música Medieval: El usuario camina por una sala en la que se hallan presentes modelos tridimensionales de algunos instrumentos medievales que aparecen esculpidos en las figuras de los músicos del Pórtico de la Gloria del la Catedral de Santiago de Compostela. Al acercarse a cada uno de ellos y mientras lo mira, el instrumento virtual hace sonar su melodía para que el visitante perciba su timbre particular.

- Mundo de la Pintura: El visitante se encuentra en una sala en la que pueden verse dos cuadros de autores del movimiento surrealista. Al caminar, atravesando uno cualquiera de los marcos, como Alicia a través del espejo, se ve a sí mismo inmerso en una versión tridimensional de la pintura, tal como podría haber figurado la escena el pintor en su mente antes de ser plasmada en las dos dimensiones del lienzo. Tras pasear por el mundo onírico del artista, el visitante puede caminar hasta un cilindro semitransparente ubicado en él que actúa como cabina de teletransporte y que le devuelve a la galería original, desde la que puede acceder a la siguiente pintura para entrar en su versión tridimensional. (fig. 5)

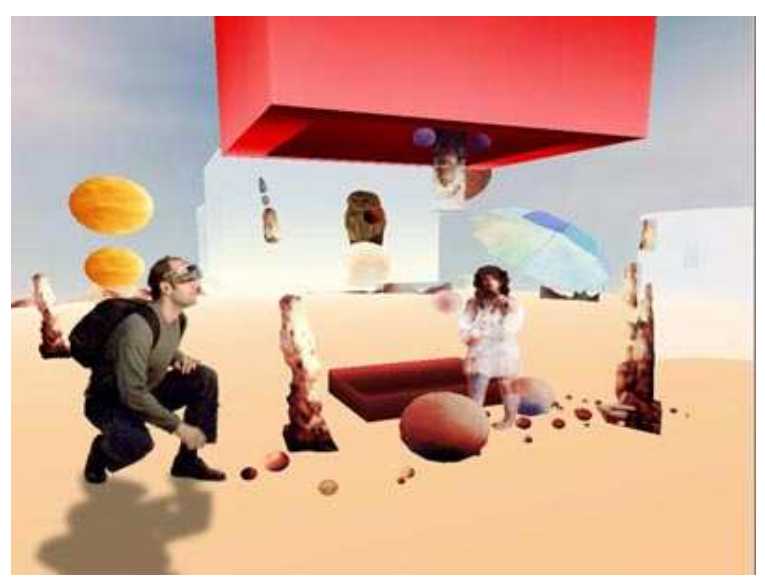

Figura 5. El mundo de la pintura

- Mundo de las artes de Galicia: Un espacio virtual compartido por cuatro usuarios en el que aparecen áreas destacadas por su color azul. Cada usuario activa el contenido del área deseada al acercarse a la misma, sin interferir por tanto con la visita de los demás visitantes. Las diferentes áreas contienen ejemplos de las siete Artes, a su escala real. A fin de que los visitantes puedan verse entre ellos, se representan en el mundo virtual como figuras de cerámica tradicional que reflejan sus movimientos.

- Mundo Castrexo: En este espacio virtual se recrea una unidad habitacional del Castro de San Cibrao de Las, correspondiente a una vivienda, patio y entorno de dicho asentamiento celta. El usuario puede deambular por la estancia principal, en la que se reproducen elementos de la cultura material de la época hallados en las excavaciones, tales como piezas de cerámica, restos de piedras del hogar, etc, a la vez que puede observar su uso por parte de habitantes virtuales que ocupan el espacio a la vez que el usuario mismo (fig. 7) (HERNANDEZ 2007)

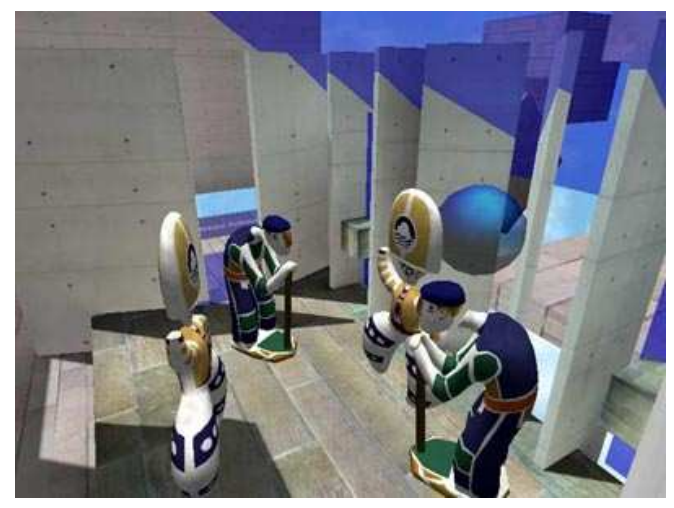


Figura 6. Avatares en el mundo de las artes

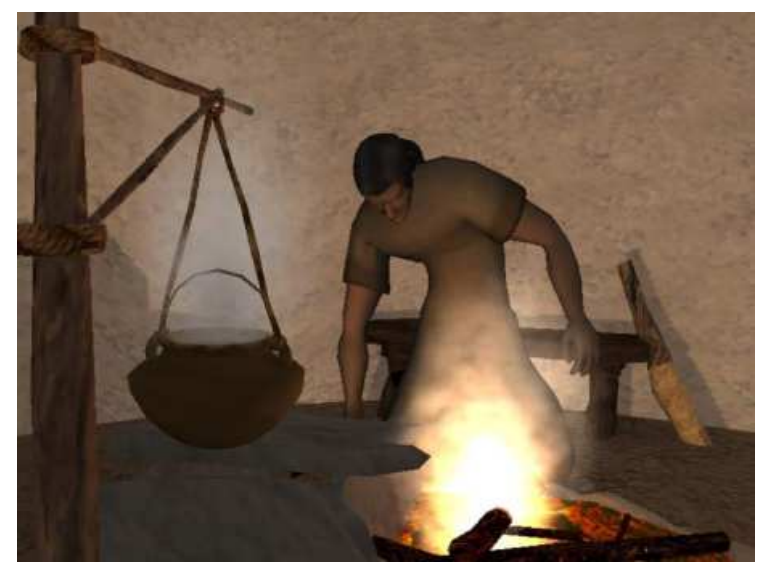

Figura 7. Habitante del mundo castrexo.
El museo Vacío entró en funcionamiento en 2002, con una instalación fija y una desmontable para la exposición itinerante. Fue retirado en 2008 para dar cabida a otras instalaciones más adecuadas a la logística de la exposición en los últimos años, dirigida a acoger grupos numerosos en visitas guiadas.

\section{Conclusiones}

Existen múltiples facetas del patrimonio cultural que solo pueden ser mostradas a través de su experimentación por medio de instalaciones audiovisuales interactivas, haciéndose perceptible a través suyo en lo que actualmente se define como patrimonio e-tangible.

Galicia Dixital constituye un ejemplo de exposición en la que se materializa este concepto, y en ella el Museo Vacío es una muestra de integración inmersiva del visitante dentro del mismo.

- Otros mundos virtuales: para esta instalación recrean entornos destinados a los niños, versiones del Camino de Santiago, descripción de la pesca tradicional en Galicia o la recreación de una tormenta en el mar.

\section{Bibliografía}

OTERO, A. ; MARTÍN, R.; GUTIERREZ, E.; FLORES, J. (2007) Simulación virtual de una tradición medieval: O 'Botafumeiro'. I Simposio de Informática Gráfica y Patrimonio Histórico (SIGPHI), 2007

HERNÁNDEZ, Luis; TAIBO, Javier; SEOANE, Antonio. (1999) Una Aplicación para la Navegación en Tiempo Real sobre Grandes Modelos Topográficos. Actas del IX Congreso Español de Informática Gráfica CEIG. Jaen, Julio 1999.

MILEKIC, S. (2006) Magic and Multimedia. Actas de Archives and Museums Informatics: Museums \& The Web 2006.

JOCH, A. (2004) In museums, no stodginess on display. Architectural Record Digital. Versión en línea

http://nano.arts.ucla.edu/nano_pub_updates04/2004_archrec/arch/features/digital/archives/0401da-1.html.

HERNÁNDEZ, Luis, TAIBO, Javier, SEOANE, (2001) Antonio Immersive video for virtual tourism. Proc. SPIE Vol. 4520, p. 63-73, Video Technologies for Multimedia Applications, 2001

HERNÁNDEZ, Luis, TAIBO, Javier, SEOANE, Antonio, LÓPEZ, Ruben, LÓPEZ, Rocío. (2003) The Empty Museum: Multi-user Interaction in an Immersive and Physically Walkable VR Space. International Conference on CYBERWORLS. 2003

HERNANDEZ, Luis, TAIBO, Javier, BLANCO, David, IGLESIAS, José, SEOANE, Antonio, JASPE, Alberto. (2007) Physically Walking in Digital Spaces - A Virtual Reality Installation for Exploration of Historical Heritage International Journal of Architectural Computing, Volume 5, Number 3, September 2007 